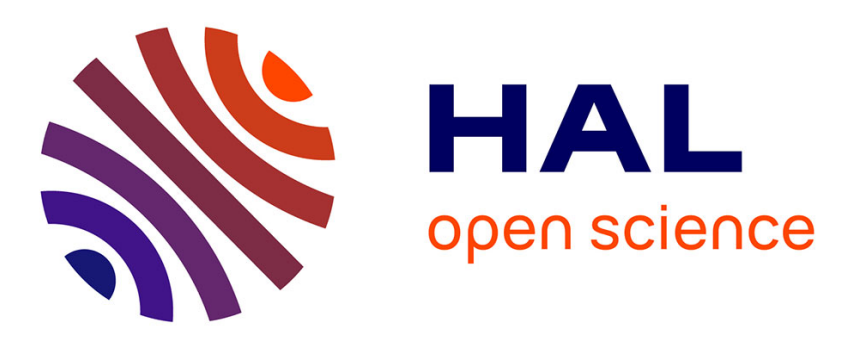

\title{
Multi-physics modeling of a permanent magnet synchronous machine by using lumped models
}

N Bracikowski, Michel Hecquet, Pascal Brochet, Sergey V. Shirinskii

\section{To cite this version:}

N Bracikowski, Michel Hecquet, Pascal Brochet, Sergey V. Shirinskii. Multi-physics modeling of a permanent magnet synchronous machine by using lumped models. IEEE Transactions on Industrial Electronics, 2012, 59 (6), pp.2426-2437. 10.1109/TIE.2011.2169640 . hal-01713715

\section{HAL Id: hal-01713715 \\ https://hal.science/hal-01713715}

Submitted on 20 Feb 2018

HAL is a multi-disciplinary open access archive for the deposit and dissemination of scientific research documents, whether they are published or not. The documents may come from teaching and research institutions in France or abroad, or from public or private research centers.
L'archive ouverte pluridisciplinaire $\mathbf{H A L}$, est destinée au dépôt et à la diffusion de documents scientifiques de niveau recherche, publiés ou non, émanant des établissements d'enseignement et de recherche français ou étrangers, des laboratoires publics ou privés. 


\title{
Multi-physics modeling of a permanent magnet synchronous machine by using lumped models
}

\begin{abstract}
This paper describes the modeling of a permanent magnet synchronous machine by using lumped models. Designing electrical machines necessarily involves several fields of physics, such as electromagnetics, thermics, mechanics and acoustics. Magnetic, electrical, electronic and thermal parts are represented by lumped models, whereas vibro-acoustic and mechanical parts are represented by analytical models.

The aim of this study is to build a design model of a permanent magnet synchronous machine for traction applications. Each model is parameterized in order to optimize the machine. The method of taking into account saturation and movement is described. These fast, lumped models make it possible to couple the software used with optimization tools. Simulation results are presented and compared with the finite element method and the experiments performed.
\end{abstract}

Index Terms-AC machines, Permanent magnet machines, Electromagnetic modeling, Magnetic circuits, Converters, Acoustic noise, Mechanical factors, Torque, Vibrations, Thermal factors, Particle swarm optimization

\section{NOMENCLATURE}

$b_{c}$

$b_{s}$

$c_{p}$

$f_{c}$

$f_{H}$

$f_{r}$

$f_{s}$

$h$

$h_{c}$

$k$

l

$m$

$n_{c}$

$n_{c}$

$n_{p h}$

$p$

$r$

A

$B$

E

F

$F_{M}$

H

I

$J$

$L_{p}$

$M$

$P$

$Y_{d}$

$Z_{s}$

$\alpha_{R_{s}}$
Width of conductors $\{m\}$

Width of slot $\{m\}$

Mass heat capacitance $\{\mathrm{J} / \mathrm{kg} / \mathrm{K}\}$

Frequency of carrier wave $\{H z\}$

Frequency of harmonic $\{\mathrm{Hz}\}$

Dry friction $\{N . m\}$

Supply frequency $\{H z\}$

Convective heat transfer coefficient $\left\{W / K / m^{2}\right\}$

Height of conductors $\{m\}$

Contact heat transfer coefficient $\left\{W / K / m^{2}\right\}$

Length of wire or flux tube $\{m\}$

Natural mode $\{-\}$

Number of coil turns $\{-\}$

Number of coils per slot $\{-\}$

Number of phases $\{-\}$

Number of pole pairs $\{-\}$

Order of the harmonic force $\{-\}$

Cross-sectional area $\left\{m^{2}\right\}$

Flux density $\{T\}$

Electromotive forces $\{V\}$

Magnetomotive force $\{A / m\}$

Maxwell Force $\{N\}$

Harmonic $\{-\}$

Current $\{A\}$

Inertia $\left\{k g \cdot m^{2}\right\}$

Sound power $\{d B\}$

Mass $\{K g\}$

Sound power $\{W\}$

Dynamic deflection $\{m\}$

Number of stator teeth $\{-\}$

Temperature coefficient of resistivity $\{1 / K\}$

\author{
$\alpha_{H_{c}} \quad$ Temperature coefficient of coercive field $\{1 / K\}$ \\ $\lambda \quad$ Conductive heat transfer coefficient $\left\{W / K / m^{2}\right\}$ \\ $\mu_{0}, \mu \quad$ Air, Material permeability $\{H / m\}$ \\ $\rho \quad$ Resistivity $\{\Omega . m\}$ \\ $\sigma \quad$ Noise radiation factor $\{-\}$ \\ $\varphi \quad$ Magnetic flux $\{W b\}$ \\ $\Gamma_{l d}, \Gamma_{e m}$ Load and electromagnetic torques $\{N . m\}$ \\ $\Omega \quad$ Machine speed of the $\{\mathrm{rad} / \mathrm{sec}\}$
}

\section{INTRODUCTION}

$\mathbf{T}$ HE recent rapid increase in the power of computer systems and the development of software for solving complicated problems have made it possible to use precise calculation methods for analysing the magnetic fields of electric machinery. Designers must therefore predict machine behavior in terms of electromagnetic, thermal, mechanical and acoustic characteristics. Although certain well-known finite element analysis (FEA) tools are capable of computing these different motor characteristics, coupling them can be painstaking and often prohibitive in terms of computational time, particularly in optimization processes. In order to solve this problem, we use lumped models $(L M)$ that are perhaps slightly less precise than FEA but faster. These multi-physics models are implemented in software to generate the automatic parameterization of the network. The behavior of the machine is modeled by using three lumped models:

- an Electrical Equivalent Circuit $(E E C)$ with an inverter for 'electrical' and 'electronic' models,

- a Permeance Network $(P N)$ for the 'magnetic' model,

- a Nodal Network $(N N)$ for the 'thermal' model,

These different systems are expressed in matrix form and are solved according to classical Kirchhoff laws. All the models are configured so they can be linked toh an optimization algorithm later on. In this article, the first part presents the different lumped models of the permanent magnet synchronous machine (PMSM) while the second part presents the couplings between them. The second part also includes several simulation results that are described and compared with an FEA to validate the results. In the third part, the fast lumped multi-physics model is coupled with an optimization tool.

Compared to other multi-physics modeling, the originality of this study resides in the use of lumped models and in the multi-physical domains studied.

Although the sensitivity of permanent magnets has often been introduced in thermal models, it is often incorrectly assumed that permanent magnet machines are noiseless. Reduced production costs have resulted in the spread of this type of machine to many domains. Despite their low noise, 
certain areas of use demand optimal acoustic comfort, such as transport [1]. In this article, we underline the fact that the noise level of PMSM can reach more than $100 \mathrm{~dB}$. This noise level can be lead to major discomfort for users and residents. Multi-physics modeling can lead to contradictory design rules. For example, increasing the yoke height/stator diameter ratio can decrease vibrations but it will obviously penalize rotor temperature. Therefore a multi-physics design is essential.

The use of lumped models as opposed to fully analytic models allows increasing accuracy. For example, compared to [2], a permeance network can take into account local quantities: saturation, leakage, magnet temperature, torque oscillation, etc. Multiphysics finite element models can be very accurate multi-physics [3] but their prohibitive computation time presents an obstacle to performing multi-physics optimization studies. The latter can include optimization but, in addition to the classical electromagnetic domain, they concern specific domains such as the aero-thermal domain, [4], and the mechanical-acoustic domain, [5].

Lumped models seem to be a good compromise between fast computation time and accuracy. Although multi-physics lumped models exist already, the originality of our tool is that it incorporates a large number of models: magnetic, electrical, electronic, thermal, mechanical and vibro-acoustic. The tool proposed here also has the advantage of taking into account a multi-physics study for several operating points and variable speeds with different modulation strategies. Furthermore, it allows underlining the physical links between domains and highlighting contradictory design rules.

\section{Multi-PHYSICS MODELS}

The physical system studied is a synchronous machine with permanent magnets used for traction, with an inverter and a mechanical load. The input parameters of the different models are geometrical and electrical parameters, material characteristics and PWM strategies. The permanent magnets are located on the surface.

\section{A. Electrical and electronic models}

1) Electrical model: Regarding the electrical part, the classical PMSM circuit is used with a resistance, an inductance and back-EMF per phase. The difficulty of the resistance calculation (1) resides in estimating the length of the end-windings, especially in a parametric system. The value of this resistance also depends on the supply frequency $f_{s}$ and winding temperature $T_{w}$ : (2a) and (3a). The frequency effect is the sum of the skin $\left(K_{\text {skin }}\right)$ and proximity ( $K_{\text {prox }}$ ) effects [6], [7]. Coefficient $\tau$ depends on the winding distribution. The temperature of the copper evaluated by the coupling with a thermal model is presented below.

$$
\begin{aligned}
& R_{s}\left(f_{s}, T_{w}\right)=n_{c} K_{r}\left(f_{s}, T_{w}\right) R_{D C}\left(T_{w}\right) \\
& R_{D C}\left(T_{w}\right)=\frac{\rho\left(T_{w}\right) l}{A} \\
& \underline{\text { with }}: \rho\left(T_{w}\right)=\rho\left(T_{\text {ref }}\right)\left\{1+\alpha_{c o}\left(T_{w}-T_{\text {ref }}\right)\right\}
\end{aligned}
$$

$$
\begin{array}{r}
K_{r}(\xi)=K_{\text {skin }}(\xi)+\tau K_{\text {prox }}(\xi) \\
\text { with }: \xi\left(f_{s}, T_{w}\right)=h_{c} \sqrt{\pi f_{s} \frac{\mu_{0}}{\rho\left(T_{w}\right)} \frac{b_{c}}{b_{s}}}
\end{array}
$$

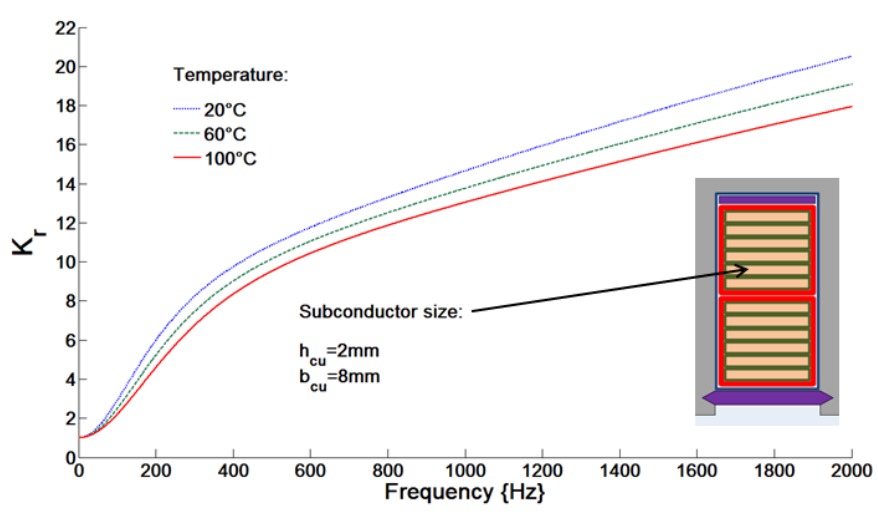

Fig. 1. Variation of $K_{r}$ versus frequency $f_{s}$ according to temperature $T_{w}$.

Moreover, the current of the phase windings is self-induced due to the leakage fluxes and fluxes that cross the air-gap. As the electromagnetic coupling is considered to be strong, the self-inductance is included in the magnetic model by the airgap and leakage permeances. The mutual-inductance is also taken into account by the magnetic model. Only the endwinding is not included in the computation of the total inductance because we considered only a two-dimensional model for the magnetic part. Also the inductance is underestimated. Therefore the end-winding inductance $L_{e w}$ can be added to the circuit. Back-EMF is computed from solutions of PN by Faraday's law of induction and is also a link with the magnetic part.

The electrical losses of PMSM are calculated by summing the copper losses for each harmonic $(\mathrm{H})$ content by the formula (4). The advantage of this formulation is that it takes the nonsinusoidal currents into account. We performed an FFT of the current in order to take into account the high frequency harmonics. $K_{r}$ is sensitive to the harmonics of higher frequencies. Fig. 1 shows the importance of $K_{r}$ variation versus frequency for one example of a winding design.

$$
P_{\text {elec }}=\sum_{H=1}^{H_{\max }} n_{p h} R_{s}\left(f_{H}, T_{w}\right) I_{R M S_{H}}{ }^{2}
$$

2) Electronic model: Concerning the electronic model, each switching cell is computed by a resistance that is either equal to a zero or infinite $\mathrm{v}$ alue. $\mathrm{T}$ he $\mathrm{i}$ nverter e nables $\mathrm{u}$ sing the PMSM at variable speed. PWM is the cause of significant harmonics in the PMSM (Fig. 2). Fig. 3 illustrates the current at full-load with PWM supply. We can see the space harmonics due to the winding distribution and the harmonics due to PWM. These additional harmonics are both a source of noise [8] and a source of losses [9].

Here, the frequency of the carrier wave $\left(f_{c}\right)$ is twentyfive times higher than the reference wave $\left(f_{s}\right)$. In reality, the frequency of the carrier wave is generally higher. 

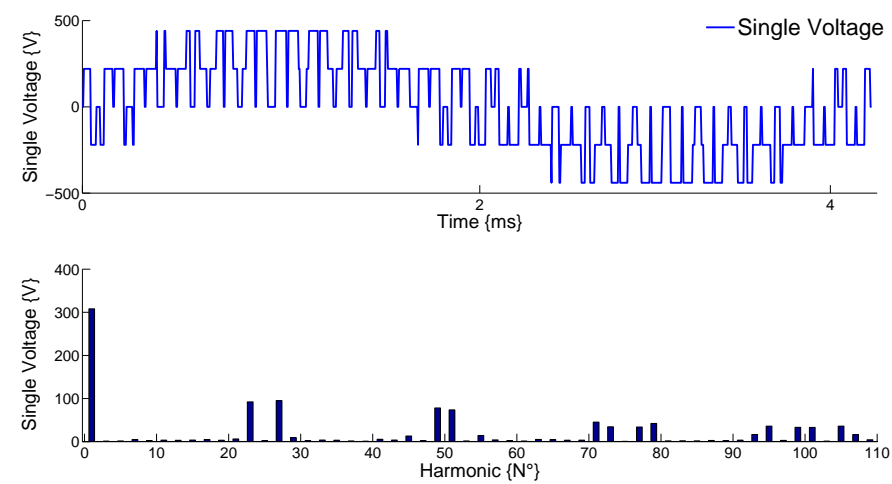

Fig. 2. Single phase voltage after PWM conversion versus time and harmonics.
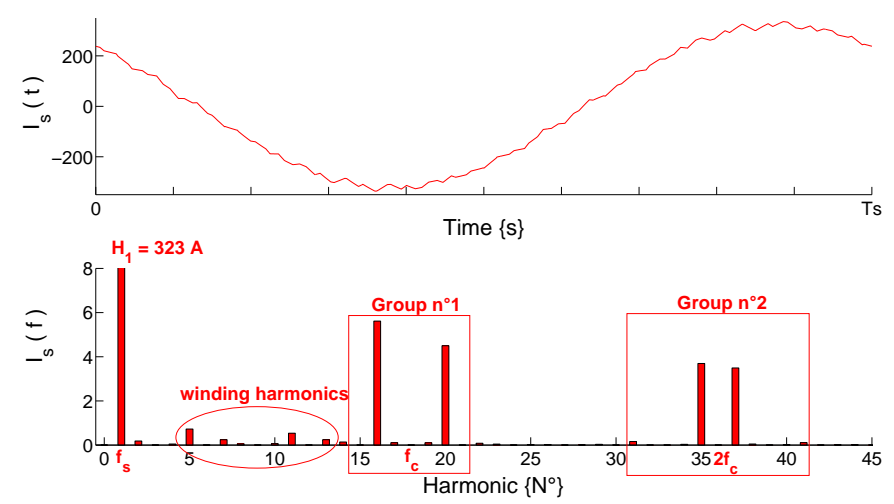

Fig. 3. Current with PWM converter versus time and harmonics in PMSM at full-load.

\section{B. Magnetic model}

The magnetic circuit of an electric machine can be modeled by a Permeance Network (PN). Each part of the magnetic circuit is symbolized by its permeance [10]. The network's topology is chosen according to geometrical considerations based on knowledge of the general direction of flux tubes (Fig. 4 ) and is completely parameterized. Symmetry conditions are considered when possible. The permeance is computed by (5).

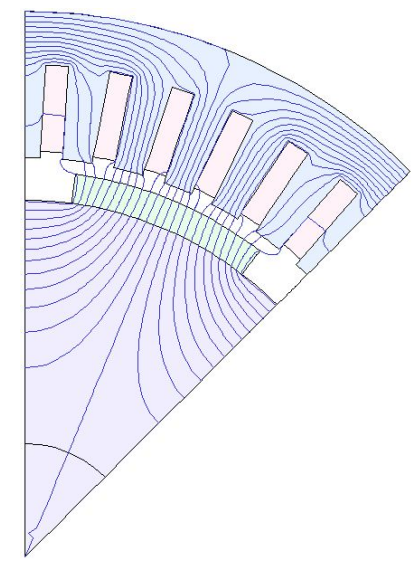

Fig. 4. An example of a flux path in one pole of the PMSM with no-load by using the Finite Element Method.

$$
\Lambda=\left\{\int_{0}^{l} \frac{d x}{\mu(x) A(x)}\right\}^{-1}
$$

PNs are configured for materials with linear permeability, but a saturation effect is included in the characteristic of flux versus permeance (according to the data of curve $\mathrm{B}(\mathrm{H})$ materials) [11]. In Fig. 5, an example of a PN for a PMSM is shown.

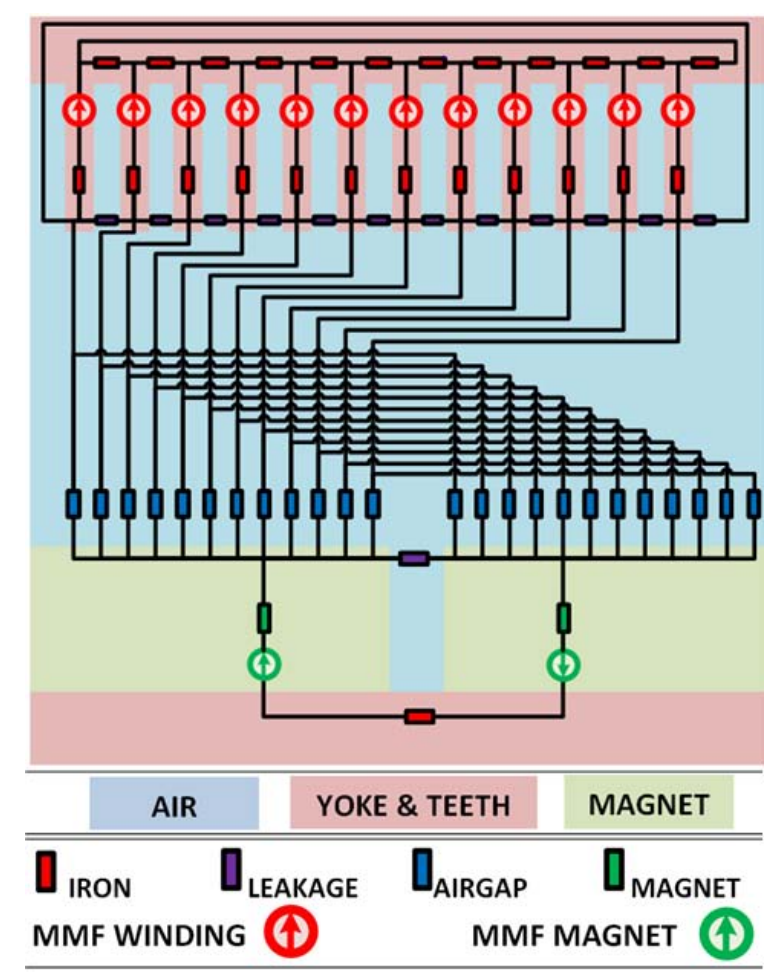

Fig. 5. Example of a Permeances Network for a PMSM.

Sources of Magnetomotive Force due to the currents and the number of coils are coupled to an electrical model which allows a linked resolution of the system of electric and magnetic equations (cf. coupling part). This type of model can also take into account movement through the air-gap permeance, which is defined periodically due to the symmetry of the PMSM according to the mechanical angle $\left(\theta_{\text {meca }}\right)$ of the machine. This aspect will be discussed more precisely below.

1) Air-gap permeance: Modeling the air-gap of an electrical machine is the most delicate part. Most of the energy is located in the air-gap. According to need, we could limit ourselves to a global permeance for the air-gap [12] or discretize the PN tooth by tooth with greater accuracy [13]-[16]. The slotting effects are not directly integrated in the air-gap permeance. One air-gap permeance was positioned for each stator tooth and permanent magnet (Fig 5). Fig. 16 shows the harmonics of the ripple torque due to the slotting effect for this network. Moreover, the tool integrates several parameterized discretizations of the PN (cf. Annexes). The discretization of the network was changed, as in Fig. 24, to observe the slotting effect as a function of space.

Certain permeance points as a function of rotor position were computed analytically or by FEA. The other points were 
calculated by spline interpolations.

The difficulty of the analytical part was to reach a sufficient number of points for correct interpolation. Here, some points were deduced by assimilating the field lines in the air-gap with geometric forms (cf. Appendix) [17]-[20]. An initial spline interpolation was performed in order to add points in the bends of the curve. This step was taken to avoid oscillations in the curve. The derivative was important in order to compute the torque of the machine. Finally, a second interpolation was performed to achieve the determination. The validation of the analytical evolution law and its derivative obtained by the finite element method is presented in Fig. 6.
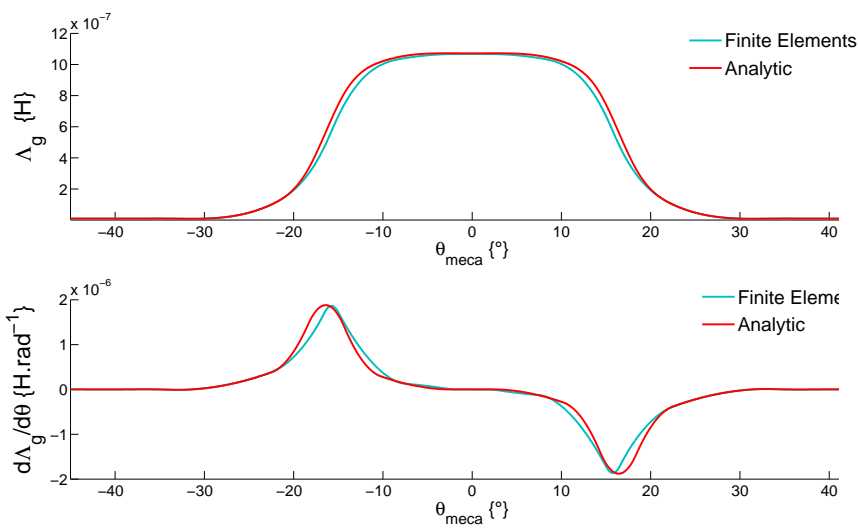

Fig. 6. Validation of the evolution law of the air-gap permeance and its derivative

The finite element method has the advantage of accuracy but requires much longer preparation time, particularly for the mesh. The aim is to combine these models with an optimization tool, hence we use the analytical method in the following. Another reason is that analytical formulation is easily configurable (Fig. 7) and quick.

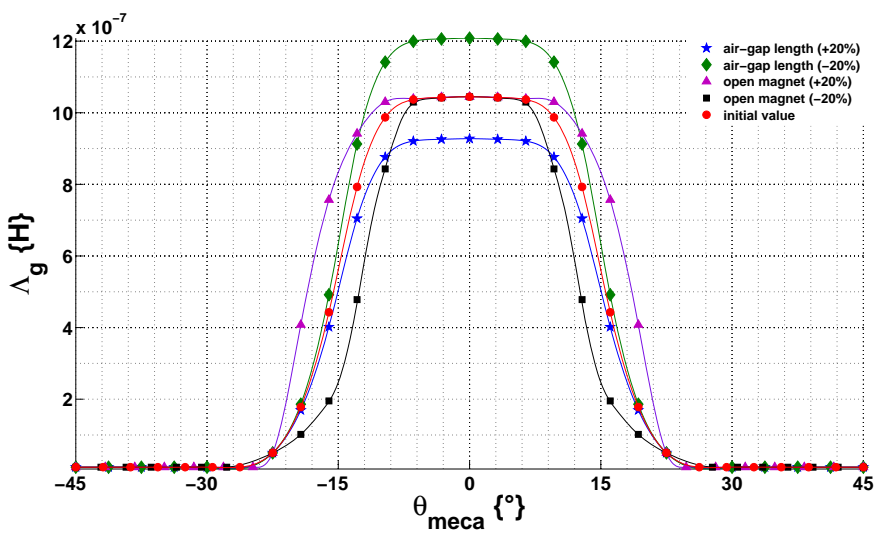

Fig. 7. Several evolution laws of the air-gap permeance

2) Magnetic losses: Iron losses from the stator are computed by using Steinmetz's formula (6).

$$
P_{\text {magn }}=M_{i r} \sum_{H=1}^{H_{\max }} K_{i r} f_{H}^{\delta} B_{i r_{H}}^{\gamma}
$$

This equation takes into account hysteresis and eddy current losses. We also performed an FFT of the flux density in order to take into account the high frequency harmonics. The advantage of this relation is that the coefficients can be easily calculated by linear regression on loss curves. For example, for M400-50A steel, $K_{i r}, \delta, \gamma$ are equal to $3.8 \times 10^{-3}, 1.54$ and 1.84 respectively. This formulation is correct for the linear part of $\mathrm{B}(\mathrm{H})$ curve and begins to diverge for high frequencies, above one $\mathrm{kHz}$ (Fig.8). To improve this determination, hysteresis and eddy current phenomena can be studied separately [21], [22], but in this case, the parameters of the equations are not directly available and experimental measurements are necessary to adjust the model. Furthermore, the work of [23] is used to determine the slot ripple losses in the rotor yoke and magnet.

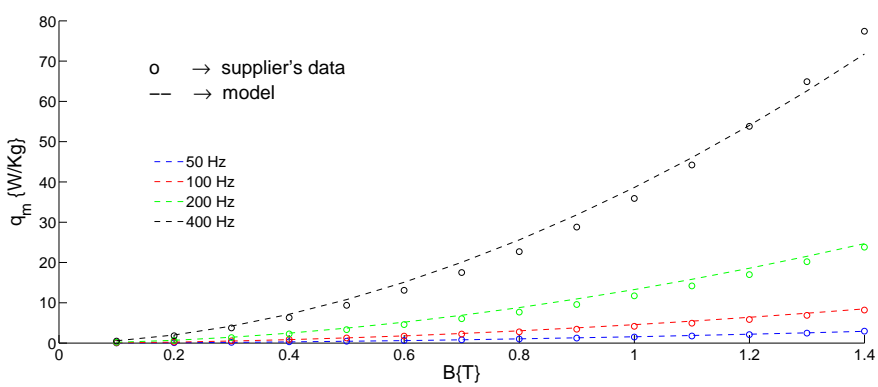

Fig. 8. Iron losses versus frequency and flux density

\section{Thermal model}

The thermal model is a nodal network [24], [25]. The main aim of this model is to estimate the temperature in the magnets in order to avoid demagnetization (Curie temperature). Changes of stator resistance and coercive field as a function of temperature are also taken into account. Fig. 9 presents an example of a PMSM for an NN. It is a two-dimensional NN model. Only $\frac{1}{2} Z_{s}$ of the PMSM machine is necessary due to the symmetries. The axial dimension can be added. It allows taking into account phenomena such as the mechanical losses in bearings, estimating the temperature in the end-windings, heating of air in the air ducts, etc. Air-gap flows are considered only in the direction tangential to the air-gap. Air displacement is due only to the motion of the rotor relative to the stator.

The part of the radial model has 8 nodes and provides a map of average temperatures in different areas of the machine. Five heat sources take into account the iron and copper losses. The losses are assumed to be constant for one computational step and the temperature of the previous step is used as the initial temperature. The motor is completely closed and selfventilated, with a fan blowing air axially around the carcass. This condition allows the assumption of a fixed temperature modeled by a temperature source $\left(T_{a m b}\right)$, equivalent to the current source of the electrical circuit.

1) Thermal Coefficients: The conductive heat transfer coefficient $(\lambda)$ value depends on the temperature of the material. The higher this value is, the more the material conducts heat. The stack of laminations used to limit eddy currents in the 


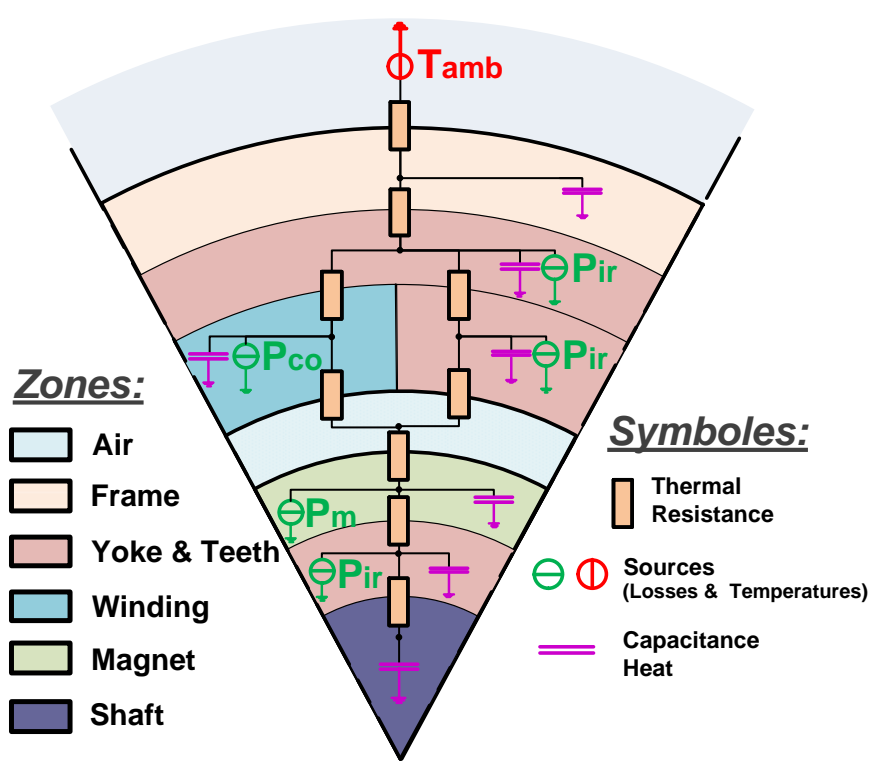

Fig. 9. Example of Nodal Network for PMSM.

iron and their impregnation makes it difficult to estimate their axial thermal conductivity, but the radial thermal conductivity is relatively well known.

The contact heat transfer coefficient $(k)$ is due to imperfect contact between two areas and is of essentially experimental origin. It greatly depends on the manufacturing process and is thus difficult to predict. Several orders of magnitudes are recalled in [6], but the extended range of variation makes it difficult to use.

The convective heat transfer coefficient $(h)$ is determined according to the dimensionless Nusselt number $(\mathrm{Nu})$. This represents the ratio between the conductive thermal resistance and the convective thermal resistance. Its estimation can only be achieved experimentally. However, many correlations exist in the literature that allow finding semi-empirical laws for computing the Nusselt number according to type of flow, geometry, etc. The Nusselt number is often formulated by using a function with Prandtl $(P r)$ and Taylor $(T a)$ numbers. The Taylor number is an important link with the mechanical model as it depends directly on the speed of the machine $(\Omega)$. Here, the Nusselt number is determined by using the works of [26]. We can find evolution of convective heat transfer coefficient versus speed in [27].

$$
\begin{gathered}
h(\Omega)=\lambda_{g} N u / L_{g} \\
N u=C \operatorname{Pr}^{\alpha} T a^{\beta}(\Omega)
\end{gathered}
$$

$L_{g}$ : Characteristic length of the air-gap;

$\lambda_{g}$ : Conductive heat transfer coefficient of the fluid;

$C, \alpha, \beta$ : Coefficients of the semi-empirical laws ;

2) Components of the Nodal Network: The model has nine thermal resistances that quantify the ability of the components to let the heat flow circulate from one node to another. Each resistance can be composed of different components: conductive thermal resistance, convective thermal resistance and contact thermal resistance.

Conduction thermal resistance is a transfer mode that takes place within the same material. It occurs in both the solid and motionless gaseous parts and is calculated by (9):

$$
R_{c d}=\int_{0}^{l} \frac{d x}{\lambda(x) A(x)}
$$

The imperfect contact between two adjacent solid areas is represented by contact thermal resistance calculated by the following formula (10):

$$
R_{s u}=\frac{1}{k A}
$$

Convective thermal resistance is a mode of heat transfer with a movement of mass due to the intervention of a fluid (gas or liquid). It is calculated by (11):

$$
R_{c v}=\frac{1}{h A}
$$

Finally, seven capacitance heats are added to quantify the ability of the material to absorb or restore energy during transient phenomena. They depend on the mass heat capacitance $\left(c_{p}\right)$, that is to say the thermo-physical property for one kilogram of the material considered. In the case of electric machines, it can be considered as classical as it depends linearly on temperature. The calculations are performed by using the following formula:

$$
C=c_{p}(T) \times M
$$

\section{Vibratory model}

Regarding the acoustic part, we propose studying the magnetic noise of the PMSM. Indeed, in electric transport system applications (variable speed and high power), the acoustic comfort of passengers and the residents of surrounding buildings are crucial. Although cogging and ripple torques must be reduced, this does not necessarily lead to low noise levels. [28] shows that the reduction of cogging torque does not automatically lead to low machine noise radiation. In the last part of this paper, we show that we obtain the same conclusion.

Only the stator part and the frame of the PMSM are considered in this model and are represented by an equivalent tube [29]. The rotor is assumed to be a negligible noise source due to its confinement.

1) Natural mode: The natural frequencies of the stator are determined by an analytical approach [2]. Many validations were performed by FEA analysis and experiments to validate the analytical model (Tab. I). In the case where the $m$ is equal to 1 , the Maxwell forces have an effect on the center of gravity of the rotor. No change of stator form is involved. The rotor shaft is subject to bending. Therefore this mode does not appear in this table. It can also determine a spring-mass system of the stator of the PMSM for each natural frequency. 
TABLE I

COMPARATIVE TABLE OF RESONANCE FREQUENCIES FOR EACH MOD

\begin{tabular}{l||c|c|c|c} 
Mode & 0 & 2 & 3 & 4 \\
\hline \hline Analytic Method $\{\mathbf{H z}\}$ & 2736 & 308 & 871 & 1670 \\
\hline Experimental Method $\{\mathbf{H z}\}$ & 2855 & 376 & 1004 & 1720 \\
\hline Error $\{\%\}$ & -4.2 & -18.1 & 13.3 & -2.9 \\
\hline
\end{tabular}

2) Exciting mode: The model is in two dimensions a only radial deflections are considered in the machine. assume that the axial deflection can be neglected. That is $\mathrm{w}$ we have made the hypothesis that the PN only gives the rac component of flux density in the airgap. These deflections the exciting mode are due to the Maxwell forces (13) and are applied on the inner surface of the stator.

$$
\frac{d F_{M}(t, \theta)}{d A}=\frac{B_{g}(t, \theta)^{2}}{2 \mu_{0}}
$$

$B_{g}(t, \theta)$ : Air-gap induction versus time and space;

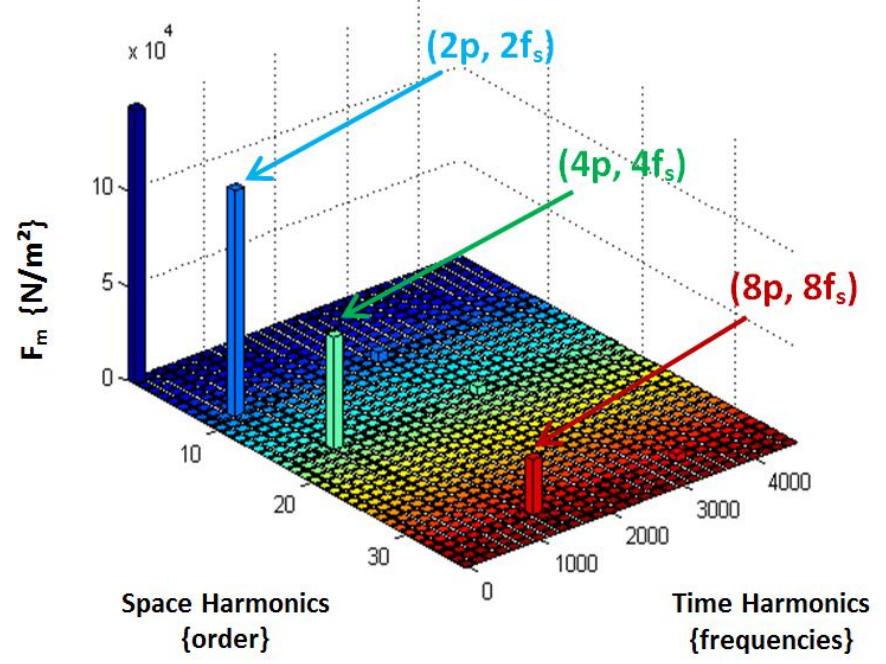

Fig. 10. Two-dimensional FFT of Maxwell forces

The radial forces are then assumed to be the only source of magnetic noise whereas the deflections in the axial direction are assumed to be uniform. The Maxwell forces are decomposed in the same way in the two-dimensional FFT of the air-gap electromagnetic pressure distribution, where an infinite wave rotating force appears as a function of order and frequency (Fig. 10). Therefore the static deflections are first computed according to the complex amplitudes of the twodimensional FFT of the pressure. The dynamic deflections $\left(Y_{d}\right)$ are then computed by an amplification factor (Fig. 11). This static/dynamic transformation integrates the modal damping coefficient (analytic formula using an experimental law [29]).

3) Resonances: Resonance phenomena may occur when there is a spatial coincidence between the order of the harmonic force and the number of natural modes, and a temporal coincidence between the frequency of the harmonic force and

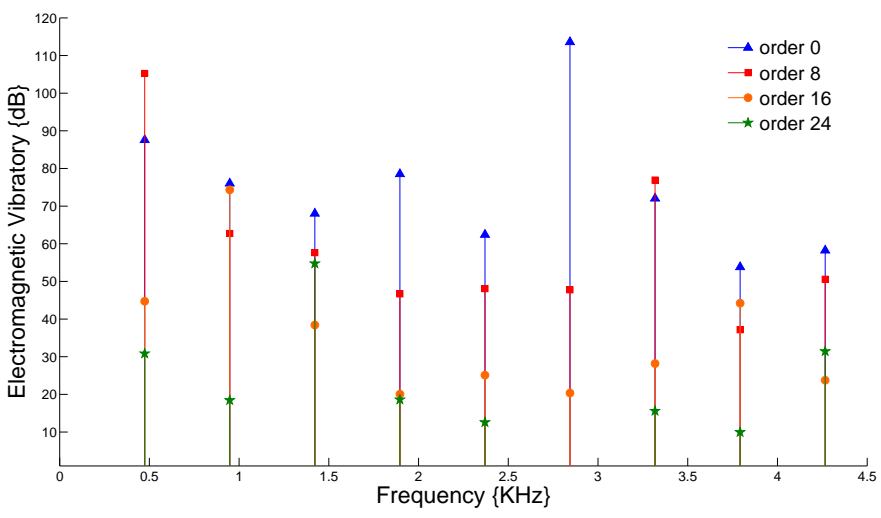

Fig. 11. Spectrum of electromagnetic vibrations for $\mathrm{N}=3555 \mathrm{rpm}$

the natural frequency. These resonances involve a significant noise level.

\section{E. Acoustic model}

The acoustic radiation of the machine can be deduced from the vibratory model [30]. The sound power in decibels $\left(L_{p}\right)$ is obtained by the following equation (14):

$$
\begin{gathered}
L_{p}=20 \log \left(\frac{P}{P_{0}}\right) \\
P=\sigma \frac{8200 S_{\text {ext }} f_{s}^{2} Y_{d}^{2}}{2 m+1}
\end{gathered}
$$

$(P)$ is the sound power in Watts radiated by an electrical machine for one mode $m$ and one frequency $f_{s} . P_{0}$ is the value corresponding to the beginning of human perception: $10^{-12}$ Watts. $\sigma$ is the noise radiation factor of the machine and can be considered as a sphere or cylinder, depending on the size of the machine. $S_{e x t}$ is the stator outer surface and the classical value 8200 is linked to the acoustic impedance of the surrounding area of the machine (real value when there are no obstacles).

\section{COUPLings And VAlidations}

We performed a study on a machine with 48 teeth $\left(Z_{s}\right)$ and 4 pairs of poles $(p)$. The rated power of the machine is $250 \mathrm{KW}$. It provides a torque of $960 \mathrm{Nm}$ at $2500 \mathrm{rpm}$ and is used for electrical traction. All the following simulations were performed with a sinusodal supply and no-load.

\section{A. General points on the couplings}

The physical coupling between two models is intrinsically linked to their behavior and the interdependence between their physical quantities. In this case three different types of coupling were carried out:

- A weak unidirectional coupling that consisted in computing the action of one phenomenon separately on another one.

- A weak bidirectional coupling which consisted in computing the physical phenomena successively between two models.

- And a strong coupling which consisted in computing the 
physical phenomena simultaneously (during the same computing step) between two models.

A reminder of couplings between the different models is presented in the table below (Tab. II):

TABLE II

Couplings Between Models

\begin{tabular}{c||c}
\hline \multicolumn{1}{c||}{ MODELS } & CoUPLINGS \\
\hline \hline Electrical/Magnetic & strong \\
\hline Electrical/Thermal & weak bidirectional \\
\hline Magnetic/Thermal & weak bidirectional \\
\hline Magnetic/Mechanical & weak unidirectional \\
\hline Electronic/Mechanical & weak unidirectional \\
\hline Thermal/Mechanical & weak unidirectional \\
\hline Magnetic/Vibratory & weak unidirectional \\
\hline Vibratory/Acoustic & weak unidirectional \\
\hline
\end{tabular}

A synthesis of couplings between models is shown in Fig. 12.

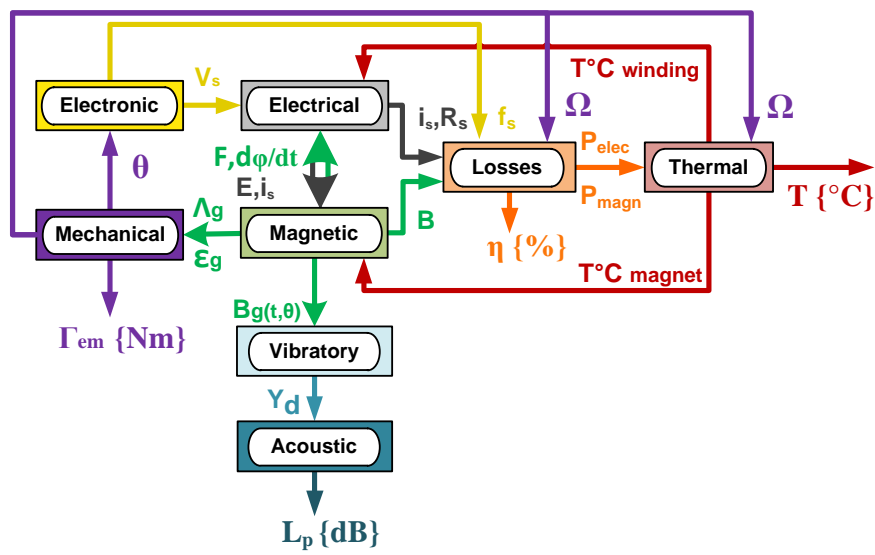

Fig. 12. Multi-physics modeling with couplings.

The input-output variables are recalled in Fig. 12 and are described in the following paragraphs. In addition, several simulations applied to our PMSM machine and comparisons are presented in this chapter.

\section{B. Electrical/Magnetic coupling}

The electromotive forces $(E)$ for each phase of the elect model are calculated by using Faraday's law of induc and are considered as the flux $(\varphi)$ flowing through the Each phase of the model is connected to the inverter creates alternative currents. The stator magnetomotive fo linked to the current phase are the source of the magr circuit. A closed loop around the slot is considered in o to establish the link between the electric currents and magnetomotive forces $(F)$. The magnetic field circula in this loop allows you to associate a magnetomotive $\mathrm{f}$ with each slot. Finally, the classical electric and magr laws (Ampere's and Hopkinson's laws) provide a syster equations to obtain the magnetomotive force [13].

The coupling between magnetic and electrical models is represented by a gyrator (Fig. 13) with a gyration coefficient equal to $n_{s}$ : the number of coils per slot. The gyrator ensures strong coupling and allows the resolution of the electromagnetic system during the same computing step.

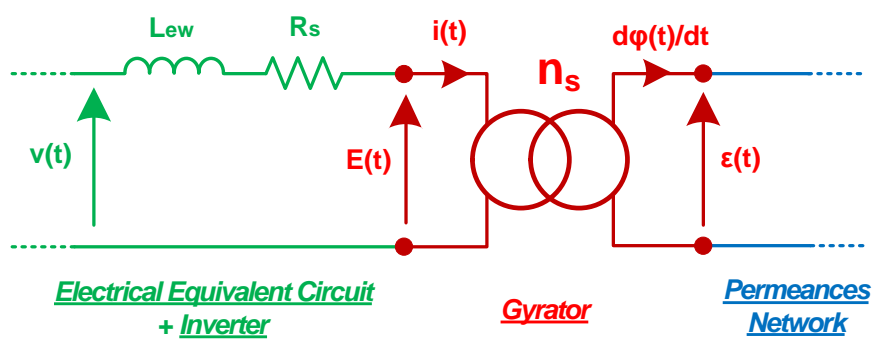

Fig. 13. Electromagnetic coupling.

Fig. 14 shows the evolution of flux density with the lumped model in the air-gap versus time and space. Only the radial component of flux density is taken into account as it predominates over the deflection of the structure. The tooth effect is visible in space when discretization is used, as in Fig. 24, while Fig. 15 presents the harmonic content of this flux density. These harmonics are obtained by the lumped models and the finite element software. The simulation results are very close to the FEA results. The harmonics $H 11$ and $H 13$ appear due to the winding distribution. The machine winding has a double layer with a step $5 / 6$ in order to reduce harmonics $H 5$ and $H 7$. The validation of back electromotive force can be found in [27].

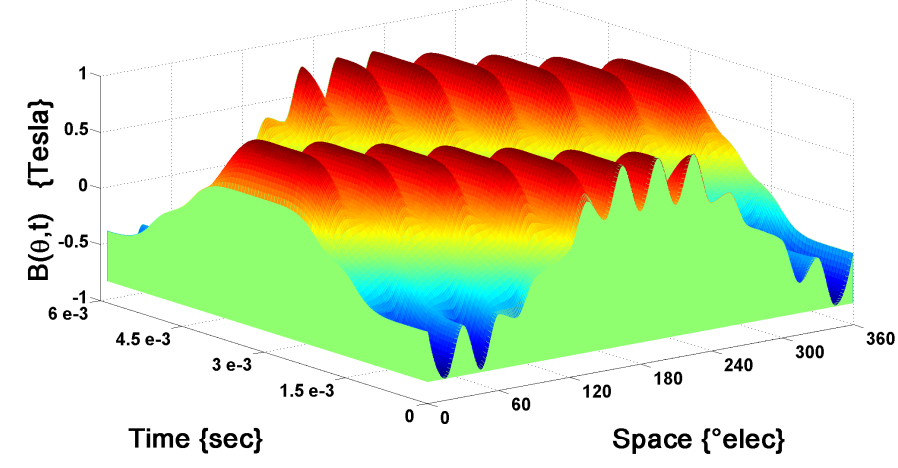

Fig. 14. Flux density in the airgap versus time and space
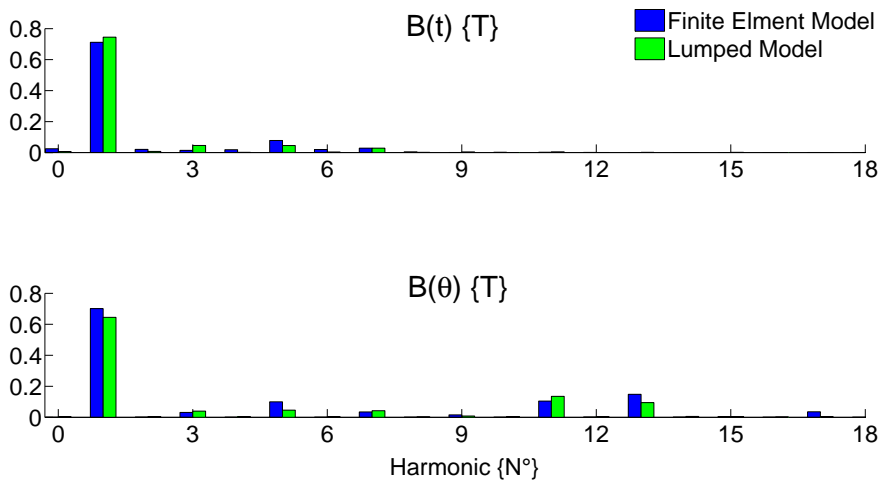

Fig. 15. Spectrum analysis of flux density 


\section{Electrical and Magnetic/Thermal coupling}

The time constants of the thermal system are much higher than the time constants of the electric and magnetic systems, explaining why the weak coupling is considered here. This coupling between electrical and thermal or magnetic and thermal is bidirectional. Regarding the Joule losses, stator resistance changes with the evolution of the temperature value. However, for the iron losses (6) of the PMSM, if the temperature changes in the machine and magnets, the coercive field also changes (16), as does the magnetomotive force of the magnet. The fluxes in the machine fluctuate, therefore changing the iron losses.

$$
H_{c}(T)=H_{c}\left(T_{r e f}\right) \times\left\{1+\alpha_{H_{c}}\left(T-T_{r e f}\right)\right\}
$$

\section{Magnetic/Mechanic coupling}

The formula for the electromechanical torque $\left(\Gamma_{e m}\right)$ of the machine is calculated by Picou's formula (17) applied to the air-gap area. It depends directly on the quantities of the magnetic model: the derivatives of air-gap permeance $(\Lambda)$ and magnetomotive forces $(\varepsilon)$ between a stator tooth $(u)$ and a rotor pole $(v)$. The magnetic and mechanical models have a unidirectional weak coupling.

$$
\Gamma_{e m}=\sum_{u, v} \frac{\partial \Lambda_{u, v}}{\partial \theta} \frac{\varepsilon_{u, v}^{2}}{2}
$$

This allows the computation of the fundamental equation of dynamics applied to solids in rotation, developed by finite difference, in order to estimate the speed of the machine as a function of time (18). It is assumed that the electromagnetic torque is equivalent to the useful torque of the machine.

$$
J \frac{d \Omega(t)}{d t}=\Gamma_{e m}-\Gamma_{l d}-f_{r} \Omega(t)
$$

In fig. 16, spectrum analysis compared to the cogging torque of the PMSM by the PN model and the FEA software. The higher magnitude of $H 12$ and multiples also appear in the PN model. It is linked to the tooth effect.

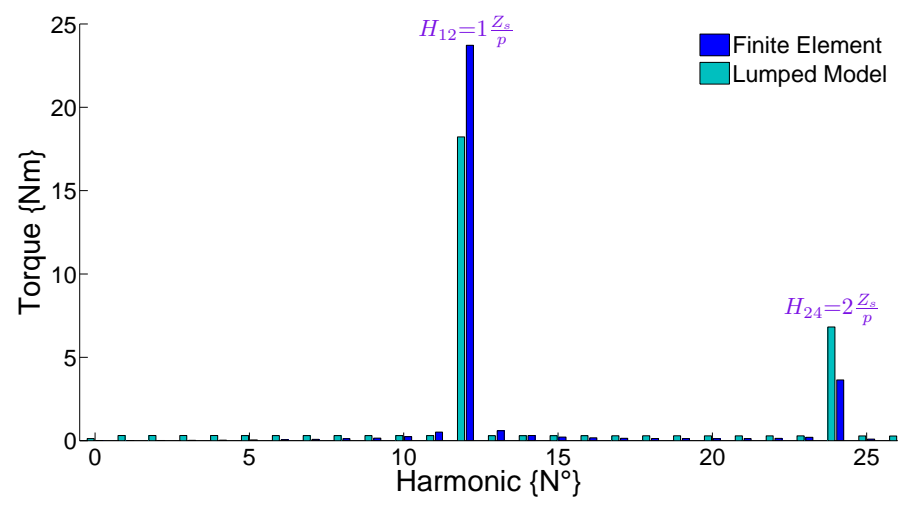

Fig. 16. Spectrum of analysis of cogging torque

The gain in computing time is highly significant for electromagnetic torque. With the same computer and the same number of positions calculated, the ratio exceeds 300 (less than $1 \mathrm{sec}$ per lumped model and $300 \mathrm{sec}$ per finite element). This provides a significant advantage when the models are used in an iterative optimization process.

\section{E. Electronic/Mechanical coupling}

This electromechanical coupling is used to simulate the motor during a path with 'torque/speed' behavior that fluctuates with time. The machine speed is controlled by the speed of the inverter switching cells of the inverter which increases the supply frequency. The level of DC voltage influence the torque (controlled rectifier or chopper). The electronic control therefore affects the mechanical aspect of the machine.

\section{F. Thermal/Mechanical coupling}

As was seen previously with the thermal model (Fig. 9), the tangential velocity in the air-gap due to the rotation of the rotor is an important parameter for computing the convective heat transfer coefficient. Therefore there is unidirectional weak coupling between the thermal and mechanical models.

\section{G. Magnetic/Vibratory/Acoustic coupling}

1) Couplings: Similarly, the induction in the air-gap according to space and time is the input variable used to evaluate the vibro-acoustic behavior of the machine (Fig. 14). The formula (13) is applied and the two-dimensional FFT of the Maxwell forces is obtained (Fig. 10). Consequently, there is unidirectional weak coupling between the magnetic and vibro-acoustic models. It is noteworthy that the deformity field is considered negligible on the magnetic state of the PMSM. Finally, the coupling between vibratory and acoustic models is also a unidirectional weak coupling. This coupling links the dynamic deflection $\left(Y_{d}\right)$ to the sound power $(P)$ by equation (15).

Changes of natural frequencies according to temperature [31] are not taken into account here. The vibro-acoustic model only has unidirectional weak coupling so can be resolved separately. This allows saving computing time

2) Experimental measurements: Four microphones were placed around the motor to record sound pressure levels and a large number of accelerometers were also placed around to motor to compare vibration and noise spectra. These signals were received by a laptop computer via a 'Bruel\&Kjaer LAN data' acquisition module, and processed by 'Pulse Labshop' software. Several sonograms were plotted and a spectrogram of the evolution of sound pressure levels was produced (Fig. 17). An initial series of tests under increasing speed were performed in order to evaluate the maximum noise, achieved at a speed of $3500 \mathrm{rpm}$. For the experimental measurements, our only possibility of the test bench supply is an AC source. 


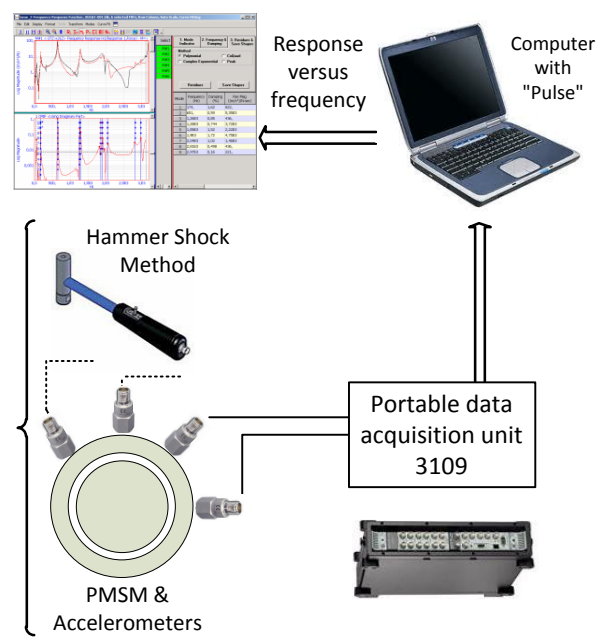

Fig. 17. Experimental vibro-acoustic measurements

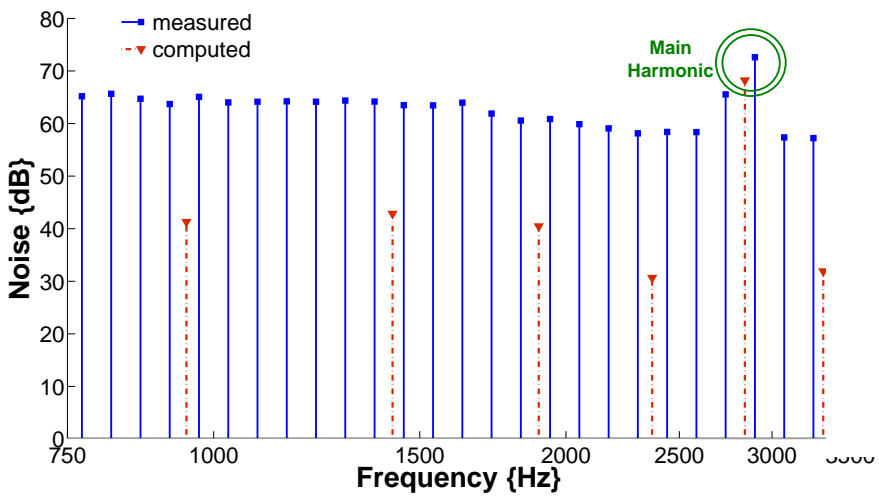

Fig. 18. Computed and measured spectra of global electromagnetic noise for $\mathrm{N}=3555 \mathrm{rpm}$

3) Results: Fig. 18 presents the measured and computed acoustic noise spectrum at $3500 \mathrm{rpm}$ with sinusoidal supply. For the experiments, resonance occurred at $2900 \mathrm{~Hz}$ leading to a sound power level of $75 \mathrm{~dB}$. This level can be assimilated with the noise level of a vacuum cleaner.

In theory, our model gives the maximum noise level at $2844 \mathrm{~Hz}$. This is due to the excitation force link with the harmonics of teeth $\left(f_{r}\right)$ associated with order $(r)$ equal to zero (19) [32]. The analytical model gives different natural frequencies that are validated by the measurements in (Table I). The resonance of the structure is possible here due to the natural deflection frequency (Fig. 11) for a mode equal to zero (breathing mode), which is close to the frequency of the harmonic force associated with the order equal to zero.

$$
r=2 \times \mu \times p \pm Z_{s} ; f_{r}=2 \times \mu \times f_{s} ; \mu=\operatorname{integer}\left(Z_{s} / 2 p\right)
$$

The advantage of our vibratory and acoustic model is that it correctly determines the frequency of the main harmonics and identifies the origin of the electromagnetic noise. Afterwards, it is possible to modify the structure or the supply strategy of PMSM in order to avoid these main resonances. The main sources of electromagnetic noise in the electrical machine are the PWM, the tooth effect and the saturation effect.

\section{OPTIMIZATION TOOL COUPLING WITH LUMPED MULTI-PHYSICS MODEL}

We developed a fast multi-physics model with a good compromise between accuracy and computation time. In order to optimize our machine for traction applications, the models were coupled to an optimization tool. It was necessary to obtain a good compromise as the influences of certain design variables ran counter to the different objectives. For example, increasing the stator height of yoke to diameter ratio decreases vibrations but clearly penalizes rotor temperature.

The optimization step was performed using Particle Swarm Optimization (PSO), a population-based stochastic algorithm that has proved to give a good balance between accuracy and computation time [33]-[35].

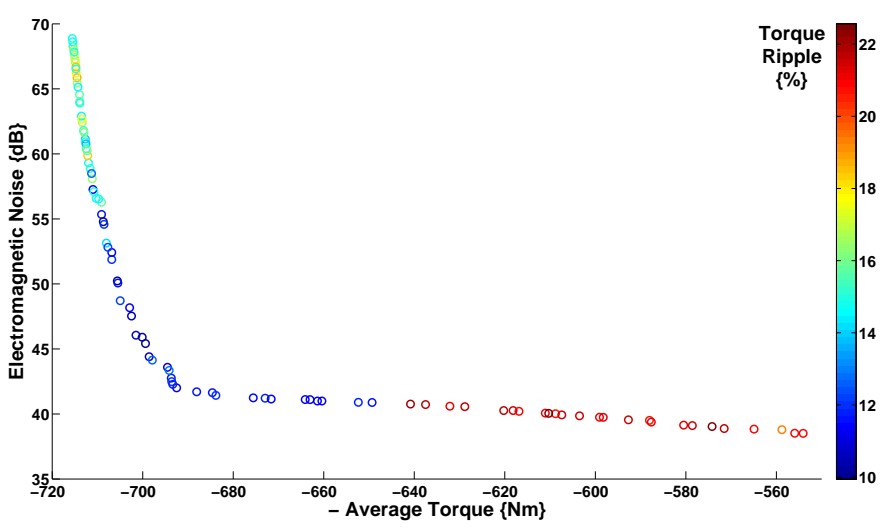

Fig. 19. Compromise between average torque and electromagnetic noise versus ripple torque $(\%)$

The objective functions of the following optimization problem were the average torque and electromagnetic noise, while torque ripple, weight and price were considered as constraints. Ripple torque was expressed as a percentage of average torque. The input parameters were all geometric: slot and magnet openings, as well as stator yoke, air-gap and magnet heights. These parameters did not influence the global volume which was kept constant throughout the process. On the Pareto front (Fig. 19), it can be seen that there is no obvious correlation between ripple torque and electromagnetic noise in the machine. Similar results can also be seen in [28]. For this case, the speed is equal to $4500 \mathrm{rpm}$ and the ripple torque has the maximum values for low noise.

\section{CONClusion}

In this paper, different lumped models of discretized electronic, electrical, magnetic and thermal components were introduced and calculated. Analytical models of mechanical and vibroacoustic components were also explained. A synthesis of couplings between the different models was presented and the input-output variables were described. Moreover, several simulations applied to our PMSM, the experimental results and comparisons with FEA software were also presented.

Lumped models can be a good compromise between an analytical design tool that is easy to implement and demands little 
computing time, and a highly accurate finite element modeling tool. All the networks presented were fully parameterized, but defined for relatively similar designs.

Compared to analytical models, lumped models take into account complex geometries and windings; they also make it possible to obtain local values and take into account local phenomena. Variable discretization can modify the compromise between time and precision.

Furthermore, compared to finite elements models, lumped models allow the analytical calculation of derivatives and are fully parameterized (thus useful in the design process). Coupling the multi-physics models was easy to implement in the same way as, for example, the coupling of economic and environmental models. The most important advantage is that the system is resolved very quickly, especially in the case of short time steps, due to the insertion of the converter, a large number of iterations in the design process, and multi-physics modeling.

Multi-physics modeling allows the designer to characterize machine behavior in several fields of physics and thus satisfy industrial quality requirements as it satisfies specifications that take into account different objective functions. For example, in multi-physics modeling, there is not necessarily any correlation between high ripple torque and high noise levels. The integration of lumped models provides more precise models, access to local values (cogging torque, magnet temperature, etc.) and easy coupling between them (compared to the finite element method) without substantially increasing computation time.

Another advantage of the tool is that it is possible to choose different network sizes: it allows more discretization and thus takes into account more phenomena, especially the eddy currents in magnets for high-speed applications. The integration of multi-physics models in optimization processes can be used to examine the sensitivity of parameters influencing the design of such machines. A global model of the machine would also help in the analysis of possible gains in terms of volume, noise, ripple torque, average torque, magnet temperature, mass, cost, efficiency, etc. and thus assist the designer to select the best machine.

\section{APPENDIX}

\section{A/ AIR-GAP PERMEANCES}

The field lines in the air-gap are assimilated to flux tubes with geometric forms: Fig. 20, Fig. 21 and Fig. 22, that are calculated respectively by: (20a), (20b) and (20c). The red arrows represent the flux direction in the flux tube.

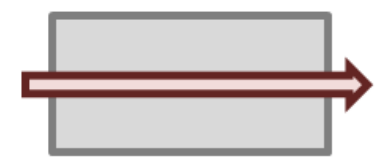

Fig. 20. Rectangular prism

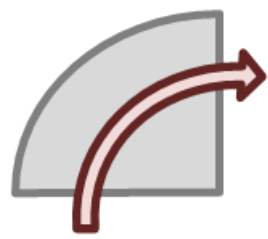

Fig. 21. Quarter-cylinder

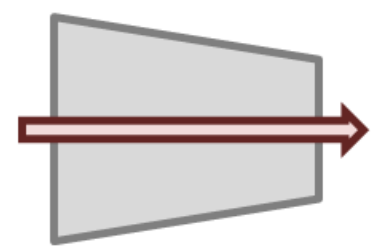

Fig. 22. Trapezoid prism

$$
\begin{array}{r}
\Lambda_{r p}=\mu_{0} \frac{h w}{l} \\
\Lambda_{q c}=\mu_{0} \frac{w}{\pi / 4} \\
\Lambda_{t p}=\mu_{0} \frac{w\left(h_{1}-h_{2}\right)}{l \ln \left(\frac{h_{1}}{h_{2}}\right)}
\end{array}
$$

With:

$w$ : Axial length of machine (parallel to the rotation axis);

$l$ : Length of flux line in flux tube;

$h$ : Height of rectangular prism;

$h_{1}$ and $h_{2}$ : High and low heights of the trapezoid prism;

\section{B/ Discretization of Permeances Network}

Fig. 23 represents a classic discretization of the PN when the machine is at load. At load, there is flux leakage in the stator slot. We find example in [16].

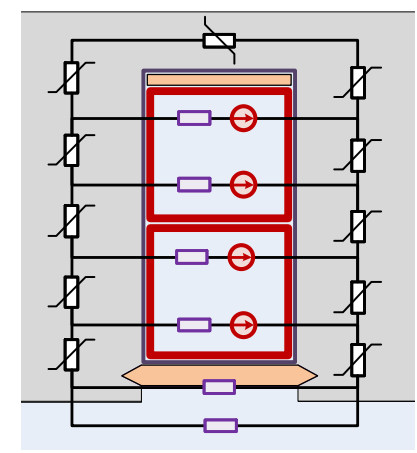

Fig. 23. example of discretization

A second discretization (Fig. 24) gives more points in the air-gap and gives better accuracy for flux density versus space. Here, this discretization has been proposed to provide the teeth effect in the space, as in Fig. 14.

\section{REFERENCES}

[1] M. Carmeli, F. Dezza, and M. Mauri, "Electromagnetic vibration and noise analysis of an external rotor permanent magnet motor," in 


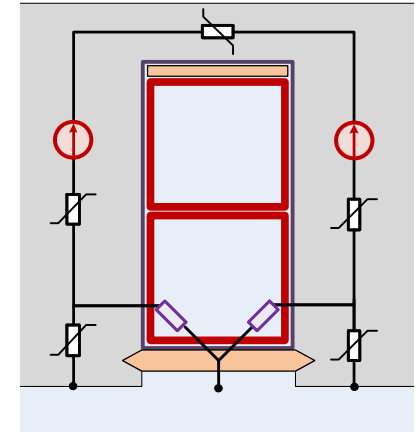

Fig. 24. example of discretization

Power Electronics, Electrical Drives, Automation and Motion, 2006. SPEEDAM 2006. International Symposium on, may 2006, pp. 1028 1033.

[2] J. Le Besnerais, A. Fasquelle, M. Hecquet, J. Pelle, V. Lanfranchi, S. Harmand, P. Brochet, and A. Randria, "Multiphysics modeling: Electro-vibro-acoustics and heat transfer of pwm-fed induction machines," Industrial Electronics, IEEE Transactions on, vol. 57, no. 4, pp. 1279-1287, april 2010.

[3] Z. Bo, Z. Jibin, and Q. Wenjuan, "Magnetic-thermal element sequential coupling algorithm in the application of permanent magnet generator temperature analysis," in Electrical Machines and Systems (ICEMS), 2010 International Conference on, oct. 2010, pp. $1804-1808$.

[4] G. Chunwei, L. Weili, and Z. Ping, "Coupled analysis on multi-physics of turbo-generator used in igcc power station," in Power System Technology (POWERCON), 2010 International Conference on, oct. 2010, pp. $1-6$.

[5] M. Van der Giet, E. Lange, D. Correa, I. Chabu, S. Nabeta, and K. Hameyer, "Acoustic simulation of a special switched reluctance drive by means of field-circuit coupling and multiphysics simulation," Industrial Electronics, IEEE Transactions on, vol. 57, no. 9, pp. 29462953, sept. 2010.

[6] J. Pyrhönen, T. Jokinen, V. Hrabovcová, and H. Niemelä, Design of rotating electrical machines. Wiley Online Library, 2008.

[7] K. Hafiz, G. Nanda, and N. Kar, "Performance analysis of aluminumand copper-rotor induction generators considering skin and thermal effects," Industrial Electronics, IEEE Transactions on, vol. 57, no. 1, pp. $181-192$, jan. 2010.

[8] W. Lo, C. Chan, Z. Zhu, L. Xu, D. Howe, and K. Chau, "Acoustic noise radiated by pwm-controllel induction machine drives," Industrial Electronics, IEEE Transactions on, vol. 47, no. 4, pp. 880-889, aug 2000.

[9] C. Larouci, "Pre-sizing of power converters using optimization under constraints," in Industrial Technology, 2008. ICIT 2008. IEEE International Conference on, april 2008, pp. 1 -6.

[10] V. Ostovic, "A novel method for evaluation of transient states in saturated electric machines," Industry Applications, IEEE Transactions on, vol. 25, no. 1, pp. 96-100, jan/feb 1989.

[11] F. Hecht and A. Marrocco, "A finite element simulation of an alternator connected to a nonlinear external circuit," Magnetics, IEEE Transactions on, vol. 26, no. 2, pp. 964-967, mar 1990.

[12] B. Cassoret, R. Corton, D. Roger, and J.-F. Brudny, "Magnetic noise reduction of induction machines," Power Electronics, IEEE Transactions on, vol. 18, no. 2, pp. 570-579, mar 2003.

[13] H. Roisse, M. Hecquet, and P. Brochet, "Simulations of synchronous machines using a electric-magnetic coupled network model," Magnetics, IEEE Transactions on, vol. 34, no. 5, pp. 3656 -3659, sep 1998.

[14] J. Farooq, S. Srairi, A. Djerdir, and A. Miraoui, "Use of permeance network method in the demagnetization phenomenon modeling in a permanent magnet motor," Magnetics, IEEE Transactions on, vol. 42, no. 4, pp. 1295-1298, april 2006.

[15] Y. Kano, T. Kosaka, and N. Matsui, "A simple nonlinear magnetic analysis for axial-flux permanent-magnet machines," Industrial Electronics, IEEE Transactions on, vol. 57, no. 6, pp. 2124-2133, june 2010.

[16] D. Petrichenko, M. Hecquet, P. Brochet, V. Kuznetsov, and D. Laloy, "Design and simulation of turbo-alternators using a coupled permeance network model," Magnetics, IEEE Transactions on, vol. 42, no. 4, pp. 1259-1262, 2006.
[17] J. Kokernak and D. Torrey, "Magnetic circuit model for the mutually coupled switched-reluctance machine," Magnetics, IEEE Transactions on, vol. 36, no. 2, pp. $500-507$, mar 2000.

[18] Y. Kano, T. Kosaka, and N. Matsui, "Simple nonlinear magnetic analysis for permanent-magnet motors," Industry Applications, IEEE Transactions on, vol. 41, no. 5, pp. 1205 - 1214, sept.-oct. 2005.

[19] Z. Zhu, Y. Pang, D. Howe, S. Iwasaki, R. Deodhar, and A. Pride, "Analysis of electromagnetic performance of flux-switching permanentmagnet machines by nonlinear adaptive lumped parameter magnetic circuit model," Magnetics, IEEE Transactions on, vol. 41, no. 11, pp. 4277 - 4287, nov. 2005.

[20] S.-H. Han, T. Jahns, and W. Soong, "A magnetic circuit model for an ipm synchronous machine incorporating moving airgap and crosscoupled saturation effects," in Electric Machines Drives Conference, 2007. IEMDC 'O7. IEEE International, vol. 1, may 2007, pp. 21 -26.

[21] Z. Gmyrek, A. Boglietti, and A. Cavagnino, "Iron loss prediction with pwm supply using low- and high-frequency measurements: Analysis and results comparison," Industrial Electronics, IEEE Transactions on, vol. 55, no. 4, pp. $1722-1728$, april 2008.

[22] M. Kazimierczuk, High-frequency magnetic components. Wiley, 2009.

[23] J. Gieras, A. Koenig, and L. Vanek, "Calculation of eddy current losses in conductive sleeves of synchronous machines," in Electrical Machines, 2008. ICEM 2008. 18th International Conference on, sept. 2008, pp. 1 -4 .

[24] J. Nerg, M. Rilla, and J. Pyrhonen, "Thermal analysis of radial-flux electrical machines with a high power density," Industrial Electronics, IEEE Transactions on, vol. 55, no. 10, pp. 3543 -3554, oct. 2008.

[25] L. Alberti and N. Bianchi, "A coupled thermal-electromagnetic analysis for a rapid and accurate prediction of im performance," Industrial Electronics, IEEE Transactions on, vol. 55, no. 10, pp. 3575-3582, oct. 2008.

[26] K. Becker and J. Kaye, "Measurements of diabatic flow in an annulus with an inner rotating cylinder," Journal of Heat Transfer (US), vol. 84, p. $97,1962$.

[27] N. Bracikowski, M. Hecquet, and P. Brochet, "Multi-physics modeling of permanent magnet synchronous machine by lumped models," in 19th International Conference on Electrical Machines, IEEE - ICEM 2010, Rome, Italy, 092010.

[28] R. Islam and I. Husain, "Analytical model for predicting noise and vibration in permanent-magnet synchronous motors," Industry Applications, IEEE Transactions on, vol. 46, no. 6, pp. 2346-2354, nov.-dec. 2010.

[29] P. Timar, Noise and vibration of electrical machines. Elsever, 1989.

[30] A. Ait-Hammouda, M. Hecquet, M. Goueygou, and P. Brochet, "Prediction of the electromagnetic noise of an asynchronous machine using experimental designs," Mathematics and Computers in Simulation, vol. 71, no. 4, 2006.

[31] S. Watanabe, S. Kenjo, K. Ide, F. Sato, and M. Yamamoto, "Natural frequencies and vibration behaviour of motor stators," Power Apparatus and Systems, IEEE Transactions on, vol. PAS-102, no. 4, pp. 949-956, april 1983.

[32] J. Walker and N. Kerruish, "Open-circuit noise in synchronous machines," Proceedings of the IEE - Part A: Power Engineering, vol. 107, no. 36, pp. 505-512, december 1960.

[33] L. dos Santos Coelho, L. Barbosa, and L. Lebensztajn, "Multiobjective particle swarm approach for the design of a brushless dc wheel motor," Magnetics, IEEE Transactions on, vol. 46, no. 8, pp. 2994-2997, aug. 2010.

[34] M. Panduro and C. Brizuela, "A comparative analysis of the performance of ga, pso and de for circular antenna arrays," in Antennas and Propagation Society International Symposium, 2009. APSURSI '09. IEEE, june 2009 , pp. $1-4$.

[35] L. dos Santos Coelho and B. Herrera, "Fuzzy identification based on a chaotic particle swarm optimization approach applied to a nonlinear yo-yo motion system," Industrial Electronics, IEEE Transactions on, vol. 54, no. 6, pp. 3234-3245, dec. 2007. 


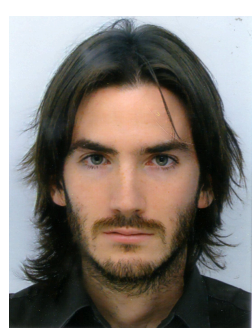

Nicolas Bracikowski received the B.Sc. and M.Sc. degrees in electrical engineering from the "Facult des Sciences Appliqus", "Universit d'Artois", Bethune, France. The Ph.D. degree is prepared in "Ecole Centrale de Lille", "Universite Nord de France", "L2EP: Laboratory of Electrical Engineering and Power Electronics of Lille", Lille, France. His area research is : optimal design of electrical machine, multi-physics modeling, lumped models.

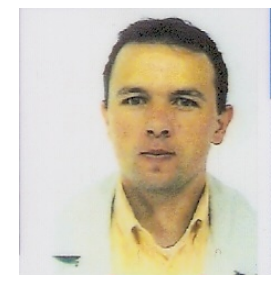

Michel Hecquet received the $\mathrm{Ph} . \mathrm{D}$ degree from the University of Lille, France, in 1995. His Ph.D dissertation presented a 3D permeance network of a claw-pole alternator, used for the simulation and the determination of the electromagnetic forces. Since 2007, he is a professor at "Ecole Centrale de Lille" in L2EP. His main interests are the development of multi-physics models of electrical machines and the optimal design of electrical machines.

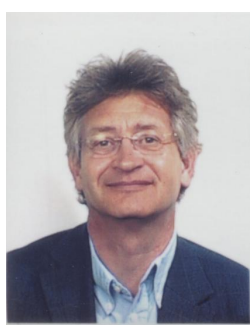

Pascal Brochet received a Ph.D. in Numerical Analysis in 1983 at the "Universite des Sciences et Technologies de Lille". He worked during seven years in an Automotive Equipment Company as a research engineer in the field of computer aided design of electrical machines. He then joined the "Ecole Centrale de Lille" in 1990 where he is now full professor and researcher at the L2EP laboratory. His main interests are numerical simulation, design and optimization of electrical machines.

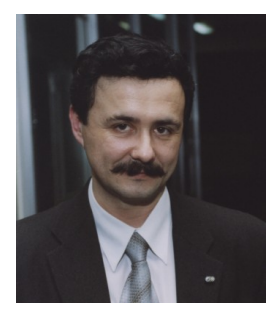

Sergey V. Shirinskii received a Ph.D. Degree in 1993 at the Moscow Power Engineering Institute, Russia. His Ph.D. thesis was devoted to simulation of motor-generator of an autonomous flywheel power storage. After graduation he works at the Moscow Power Engineering Institute, at present he is associate professor of the Department of Electromechanics. His research fields are numerical analysis of magnetic fields, development of Tooth Contour Method for simulation of electric machines by permeance networks. 